\title{
Study on Numerical Prediction of Supply Water Temperature in the Building
}

\author{
Shizuo Iwamoto', Kyosuke Sakaue ${ }^{2}$ \\ ${ }^{1}$ Kanagawa University \\ Japan \\ Iwamotos@jindai.jp \\ ${ }^{2}$ Meiji University \\ Japan
}

\section{Extended Abstract}

The energy consumption for hot water supply system is large in buildings such as dwellings, hotels and hospitals. It is sometimes up to 20 to 30 percent of the entire building energy consumption. Energy conservation and evaluation of energy consumption for hot water supply system are very important on energy saving in the buildings. Energy consumption in the hot water supply system consist on energy to make hot water from water, heat loss due to piping and in the heat sources.

Here in energy saving measures are applied for above three terms. Especially in the heat source there are solar thermal and geothermal as a natural energy and exhaust heat from cogeneration system. In recent year heat pump system and hybrid system in combination with boilers and heat pumps are becoming popular.

The efficiency of boilers is not so much affected by the supply water temperature. But that of other heat source system is sometimes affected by the temperature of the supply water. Supply water temperature is one of the important input conditions in order to evaluate and predict the energy consumption of the heat source.

In a small building such as detached houses city-pressure water system is employed and water supply temperature is equal to city water temperature. It can be estimated by linear function of mean outdoor air temperature. There is also a method to predict city water temperature from river water temperature as water sources.

The break tank is used in general and supply water temperature will be equal to tank watertemperature that is different from city water temperature. The numerical prediction method of the tank water temperature is need to estimate supply water temperature to heat source reasonably.

Therefore, this study focused on the supply water temperature in a building. It is studied by measurement and calculation to propose a general estimation method. This study represented by the following three stages.

(1) measure the tank water temperature in the real building

(2) propose the method to calculate the water temperature from the heat balance equation of water in the tank

(3) show the validity of the calculation method by comparing the measurement and calculation results

This paper shows how to formulate a water supply temperature estimation method in the buildings from these results. 